\title{
11. Progress and Historical Reflection in Philosophy
}

Thomas Grundmann, Cologne

\section{Introduction}

'Progress' is an evaluative concept. It refers to improvements over time, in contrast to periods of stagnation or even regression. We characterise events or processes as constituting progress. However, the same event may count as progress and regress at the same time, depending on the relevant respect. For example, the invention of nuclear power is technical progress, but at the same time it may be ecological regress. So when we characterise an event as progressive, we must always add the respect in which we consider it to be progressive. We can also characterise disciplines or cognitive practices as being progressive (over a certain period). We then evaluate these disciplines based on the results they produce. In these cases, the standard of evaluation is typically the discipline's cognitive goal.

There are different ways in which disciplines can be progressive. Fundamentally, one can distinguish between progress that is truth-related and progress that is not. Let me start with elucidating dimensions of disciplinary progress that are not truth-related. These dimensions of progress must be measured against cognitive values that are independent of truth. A discipline can be progressive by enlarging its problem space through adding new questions, problems, or topics, proposing additional theories, methods, and arguments, or creating richer conceptual structures. ${ }^{1}$ This is more than mere innovation. It not only changes but extends the space of objects to be understood. In philosophy, we often encounter this type of progress on the grand scale, when new paradigms of theorising enter the stage (e.g. around 1800, when German Idealism explored ways in which the mind or conceptual structure might be constitutive of reality, or around 1900, with the linguistic turn). But enlargement of a

\footnotetext{
${ }^{1}$ See Melnyk (2008) and Nudler (2001).
} 
problem space may also happen within the continuous discussion of a received problem. Consider the problem of mental causation: How can the mind cause physical events if it is not itself reducible to the physical? This problem has been discussed at least since Descartes. But the debate changed dramatically when new conceptions of causation such as Lewis' (1973) counterfactual analysis and the theory of agent causation (Chisholm 1976; O'Connor 2000) were proposed. Moreover, further new aspects of this problem were discovered when Jaegwon Kim (1989) put forward his argument from explanatory exclusion, according to which there is no causal role for distinct mental events to play if the physical world is causally closed. Progress understood as an enlargement of the problem space in all of these cases involves the availability of new tools and positions for our theorising.

One can also characterise a discipline as being progressive in a non-truth-related way if it differentiates problems, distinctions, arguments, methods, or theories over time. ${ }^{2}$ This can be done, e.g., by spelling out the details of a problem, by turning an informal worry into a formalised counterargument, or by making more and more implications of a given theory explicit. Let me illustrate this with a philosophical example. When we talk about the world, we not only mention individual things but also classify these things as belonging to common types. Platonism claims that such types are abstract, universal entities that exist independently of their instances. Aristotelians also believe that types are universals, but they restrict their existence to instantiated universals. In contrast, resemblance nominalism offers an extremely parsimonious worldview, according to which only individuals exist and all types supervene on primitive resemblance relations among these individuals. All three theories can tell a story about the nature of types. However, David Armstrong (1989) discovered that resemblance nominalism has the following, previously unobserved implication: Consider a red car, a red apple, and a green apple. Resemblance nominalism cannot explain why the car and the red apple are more similar to each other with respect to colour than the red apple and the green

\footnotetext{
${ }^{2}$ See Beckermann (2008: 609).
} 
apple. This is because resemblance nominalism can explain similarities only in virtue of resemblance relations between the primitive natures of the individuals, and it seems clear that at the fundamental level, the red apple and the green apple are more similar to each other than the red apple and the red car. Sometimes, as in this case, making implications explicit can also help us to see that a given theory has counterintuitive consequences.

Finally, one can promote progressive research programs in a discipline by making progress in solving problems in a given paradigm (see Rapaport 1982). Conflicting programs can coexist even if they are quite successful in solving their inherent problems. So such progress may not give us a criterion to decide which paradigm is true or even superior to the other. In this sense, the parallel developments of epistemic internalism and reliabilism over the last thirty years can be understood as progressive research programs. Each of them faces a number of crucial problems. The most severe problems for internalism are the threat of an unstoppable regress of justification, the worry that, when understood internalistically, epistemic justification loses its connection to truth, and cases of justified belief based on forgotten evidence. Severe problems for reliabilism are the generality problem, i.e. the question of which type of a token belief process is the relevant one when one evaluates reliability, the problem of the new evil demon, i.e. the intuition that even wholly unreliable epistemic agents can have justified beliefs, and the problem that reliabilism must classify reliable beliefs as justified even if they are not based on any evidence. Both sides address these and other inherent problems and try to come up with solutions to or dissolutions of the problems. The internalist avoids the regress problem either by referring to ultimate, selfevident justifiers or by turning towards mentalism, i.e. the theory that justification supervenes on one's non-factive mental states, and the fact that mentalism loses the objective connection with truth is often treated as a virtue rather than a vice since the intuition of the new evil demon suggests that an objective truth connection is not required for justified belief. On the reliabilist side, different solutions to the generality problem have been offered (though none 
of them so far seems fully satisfying), and in reply to the new evil demon case, reliabilists typically claim that this intuition is only about blameless belief rather than justified belief. Without going into too much detail here, it seems fair to say that although internalism and reliabilism are both progressive research programs, this has not led to general agreement about which of these is true. ${ }^{3}$

We should distinguish the preceding dimensions of disciplinary progress (i.e. enlargement of a problem space, differentiation, and progressive research programs), which are not truth-related, from truth-related progress. Of course, I do not want to dispute that ways of progressing that are not conceptually related to truth may, under appropriate circumstances, nevertheless be instrumentally valuable for achieving truth-related progress. A discipline makes truth-related progress if and only if (and as long as) it collectively tends to converge on the truth over time, i.e. its practitioners largely agree on more and more true propositions over time. This can happen through the discovery of new facts, through a correction of previous errors, or through the discovery of true explanations and true solutions to problems. Often, a discipline's truth-related progress correlates with a collective accumulation of knowledge. (Although depending on one's theory of knowledge, collective agreement on the truth may not be sufficient for achieving knowledge.)

Whereas pseudo-sciences such as astrology may make some progress that is not truthrelated - I do not see any reason why they cannot enlarge their repertoire of thinking or differentiate their cognitive resources, or why they should not be able to solve at least some of the problems they face -, it seems to be an essential feature of scientific disciplines that they make truth-related progress. The main reason for this is that truth is the aim of science, ${ }^{4}$ and our primary standard for measuring a discipline's progress should be collective convergence to the discipline's specific goal (Melnyk 2008; Dietrich 2010; Chalmers 2015: 4). Of course,

\footnotetext{
${ }^{3}$ For a comprehensive overview of the internalism-externalism debate, see Pappas (2014).

${ }^{4}$ Even scientific instrumentalists would admit that the aim of science is true predictions.
} 
it is not easy to determine whether a discipline converges to truth. Obviously, collective convergence is not sufficient for progress because it might also be convergence to the false (Chalmers 2015: 7). But it is safe to claim that without collective convergence over time, without increasing agreement within a discipline, truth-related progress of that discipline is impossible. Isolated thinkers may make some truth-related progress without general agreement, but truth-related progress of the entire discipline requires collective convergence.

There is also the question of how much truth-related progress a particular discipline makes during a specific period of time. The degree of collective convergence (which, as indicated above, is not the same as truth-related progress) can be measured along different dimensions. The following aspects are relevant here: (i) number: to what extent do relevant experts converge in their beliefs?, (ii) significance: is the disciplinary convergence limited to smaller and relatively local issues, or do we find convergence with respect to the big and fundamental questions in the field?, (iii) time: how quickly do beliefs converge on a specific answer to a question?, and (iv) linearity: is the convergence progressing in a linear way, or is it interrupted by periods of a higher diversity of views?

According to the standard view, hard sciences such as physics or mathematics behave very differently from philosophy when it comes to collective convergence of views (Kornblith (2010) is a proponent of this standard view). Of course, even hard sciences do not progress in an entirely linear way. They also undergo revolutionary periods when paradigm changes occur. Before such changes, disagreement increases, and after these changes, when a new paradigm takes over, there is a lot of disagreement as well, at least in the initial phase. However, when we focus on the period between the initial introduction of a new theory and some time in advance of the 'death' of this theory, something like the illustration in Figure 1 will be representative. At the beginning, the reactions of the experts will be strongly divergent - only a few will fully agree, while most of them will either suspend judgment or still accept conflicting theories that were successful in the past. After a while, the scope of expert 
opinions will range from suspension to full belief. Then, the collective degree of belief converges to some number close to 1 .

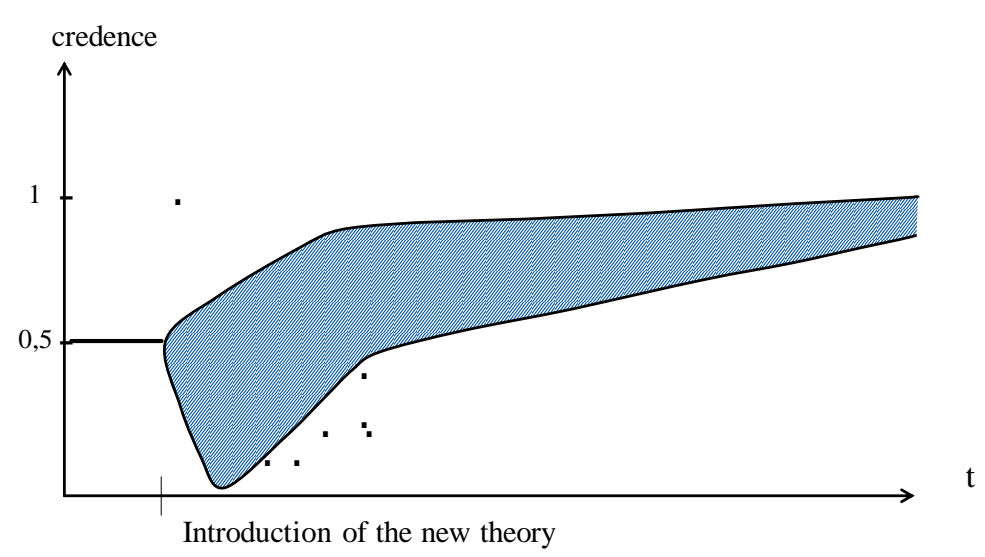

Figure 1: convergence in science

The situation in philosophy is, according to the standard view, completely different (see Figure 2). When we consider a new question in philosophy, there will be an initial phase of not knowing what to believe - here suspension of belief is the dominant position. After that, you find some polarisation such that the tendency to either strong belief or strong disbelief increases. Later on, philosophical views seem to be randomly distributed, with no tendency to any kind of collective convergence. This seems to suggest that there is absolutely no truth-related progress in philosophy. However, less radical positions can also be defended. In principle, three positions about the degree of truth-related progress in philosophy are possible. Skepticism about truth-related progress claims that there is no truth-related progress in philosophy. The opposite extreme is a symmetry view about truth-related progress, which claims that the degree of truth-related progress in philosophy approximates the degree of truth-related progress in the sciences. One does not find many advocates of this view, although naturalists who believe that there is a methodological continuity between philosophy 
and the sciences may be tempted to accept such a symmetry view. Then, there is an intermediate position that I will call the 'limited progress view'. According to this view, there is some truth-related progress in philosophy, but it is smaller, slower, and less significant than in the sciences.

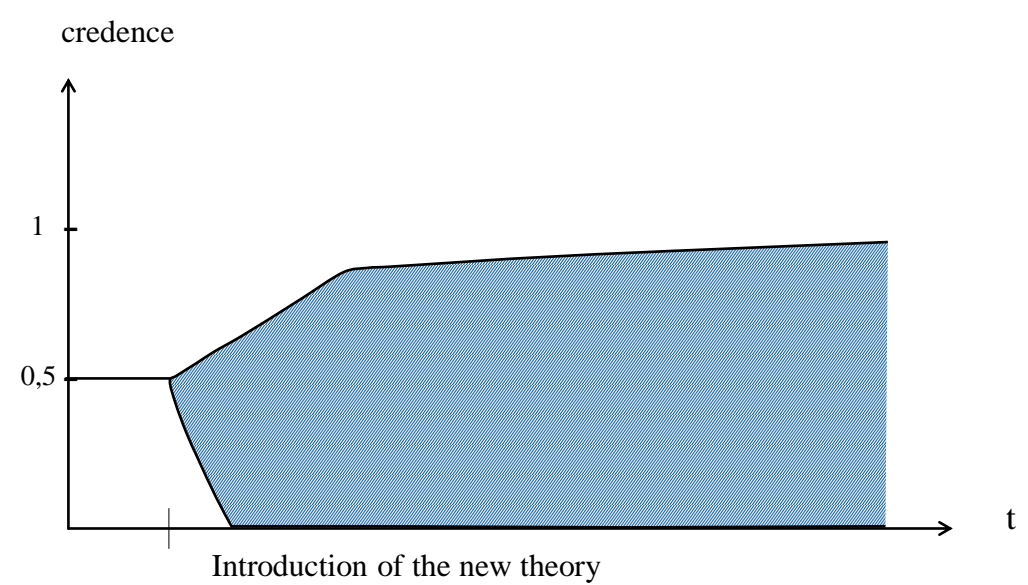

Figure 2: convergence in philosophy

In what follows, I will first consider arguments that support skepticism about truthrelated progress in philosophy, and I will argue that none of them is convincing. It will turn out that the limited progress view is the most plausible one for philosophy. Second, I will offer an explanation of the limitation of (truth-related) progress in philosophy that differs from the one offered by Chalmers (2015) in that, in contrast to Chalmers, I propose that methodological pluralism in philosophy is the key reason for the discipline's limited progress. Third, I will outline some consequences of this explanation regarding the role that the history of philosophy plays for systematic philosophy.

\section{Arguments for skepticism about truth-related progress in philosophy}


Many philosophers are explicitly skeptical about truth-related progress in philosophy. Here are some representative voices:

Philosophy is not a science, because progress in philosophy is not a matter of expanding knowledge, of acquiring new truths about the world. ... [I]t is indubitable that we know some things that the great philosophers of the past did not know. But the things we know that they didn't know are not philosophical things. (Kenny 2005: 16)

[I]t would be hard to claim that humanity today knows the answers to more philosophical questions than it did even in Plato's time, as we seem not to know the answers to any philosophical questions. ... Philosophers are no closer to achieving consensus ... than they were in Plato's day. (Melnyk 2008: 208)

[I]f one asks a physicist or biologist, a historian or a mathematician what knowledge has been achieved in his subject, he can take one to a large library, and point out myriad books which detail the cognitive achievements of his subjects. But if one asks a philosopher for even a single book that will summarize the elements of philosophical knowledge ... he will have nothing to present. There is no general, agreed body of philosophical knowledge .... (Hacker 2009: 130)

Very unlike science, no part of philosophy advances. Philosophy is, except for some modernizing, exactly the same now as it has ever been. It has not progressed one iota. (Dietrich 2010: 333) 
These philosophers seem to agree that philosophy neither accumulates collective knowledge nor shows any tendency to collective convergence.

Let us now look more closely at the arguments that are offered in favour of skepticism about (truth-related) progress. Ernst (2013) gives three arguments against progress in philosophy that are representative of many skeptics. His first argument is the argument from modesty:

Philosophers are typically reluctant to compete with the great philosophers of the past. Who would claim to understand human nature, the essence of the good, or our relation to the world better than Plato, Aquinas, or Kant? If there were progress in philosophy, this kind of modesty would be wrongheaded. However, it seems appropriate. (Ernst 2013: 8; my translation, TG)

This argument can be reconstructed in the following way:

(1) Current philosophers should not regard themselves as equal or superior to the great philosophers of the past.

(2) If philosophy is progressive, current philosophers should regard themselves as equal or superior to the great philosophers of the past.

(3) Therefore, philosophy is not progressive.

Both premises, (1) and (2), are objectionable. Premise 1 has two readings. On the first reading, we should not believe that we are equal or superior to the great philosophers of the past. This seems true since the great philosophers of the past were cognitively exceptional figures, sometimes even geniuses, and most of us would clearly be massively overconfident if we regarded ourselves as equally endowed philosophers. However, under this reading, (2) is 
false. If philosophy is progressive, its later achievements certainly benefit from the insights that were gained in the past. So we need not have a cognitive endowment that is equal or even superior to the great philosophers of the past in order to possess more philosophical knowledge than they did. Intellectual dwarfs on the shoulders of intellectual giants can still see more than the giants.

On the second reading, (1) suggests that current philosophers are not in an epistemic position that is equal or superior to that of the great philosophers of the past. But this assumption is clearly question-begging in an argument against philosophical progress. For, if philosophy really is progressive, we certainly should claim that we are currently in an epistemically better position than the great philosophers of the past. There may be a weaker understanding of the argument from modesty such that it simply reflects current philosophers' attitudes towards the great philosophers of the past. Under this interpretation, we can only conclude that current philosophers do not consider their discipline as being progressive. But this would not support the claim that philosophy is not progressive. One may also doubt the assumption that current philosophers are typically reluctant to compete with the views of the great philosophers of the past. Some current philosophers indeed claim that Plato was wrong about the essence of human nature, since he did not know what evolutionary anthropology has since discovered about the human species, utilitarians typically claim that Kant was wrong in claiming that the right has a deontological nature, and realists and externalists massively object to Kant's view that reality is partly constituted by the human mind.

Ernst's second argument for progress skepticism is the argument from education:

In contrast to the sciences, we teach philosophers by making them familiar with the philosophical tradition (e.g. Plato). Our insights cannot be simply gathered in textbooks. If there were progress in philosophy, it would not be required or 
would even be harmful to teach the thoughts of the mighty dead to our students.

(Ernst 2013: 8; my translation, TG)

Here is the rational reconstruction of this argument:

(1) We teach philosophy to students by teaching them the philosophical tradition.

(2) If philosophy makes progress, teaching the philosophical tradition is not required.

(3) Therefore, philosophy does not make any progress.

Strictly speaking, this argument is invalid. To turn it into a valid argument, one must revise (1) in such a way that teaching philosophy requires teaching the philosophical tradition. However, this revised version of (1) is controversial. At least some philosophers believe that teaching the history of philosophy to students is dysfunctional for a proper philosophical education. Most prominently, Gilbert Harman expressed this view with his famous slogan 'Say "no" to the history of philosophy. ${ }^{, 5}$ Premise (2) looks even more dubious. If philosophy were progressing quickly, then it would be unnecessary to teach the philosophical tradition for purely epistemic reasons. This much seems true. Nevertheless, (2) may be false. First, progress in philosophy is obviously much slower than progress in the sciences, because there is no accumulation of philosophical evidence through the invention of new technologies. Since the evidential basis for philosophy (i.e. rational intuitions and a priori insights) is pretty stable over time, it is reasonable to expect that the tenability of classic philosophical positions survives, in contrast with, e.g., classic physics. Second, even if there is no epistemic need to

\footnotetext{
${ }^{5}$ See Sorell (2005) for extensive quotes from his correspondence with Harman. In one quoted passage, Harman says: 'I also think ... that a study of the history of philosophy tends not to be useful to students of philosophy' (Sorell 2005: 44).
} 
teach students the philosophical tradition, there may be independent didactic reasons for this practice. Teaching the philosophical tradition might, e.g., help students grasp the 'big picture' behind certain ideas. This is something that plays an important role in philosophical but not in scientific education. So we should reject (2) anyway.

Finally, Ernst presents his argument from research. Again, here is what it says:

Even in research, classic philosophers such as, e.g., Plato are treated like contemporary colleagues. This only makes sense if there is no progress in philosophy. Otherwise, discussing classic philosophers would be a complete waste of time. This would be a discussion of positions that have long been outdated. (Ernst 2013: 8; my translation, TG)

Through rational reconstruction we get the following argument:

(1) It makes sense to treat classic philosophers like contemporary colleagues.

(2) Treating classic philosophers in such a way makes sense only if there is no progress in philosophy.

(3) Therefore, there is no progress in philosophy.

This is a valid modus ponens. However, both premises are disputable. It is true that many, though not all, current philosophers treat some classic philosophers like contemporary colleagues. But it is still another question whether this practice makes sense or is reasonable. One can dispute the latter without disputing the former. Premise (2) looks even more worrisome. First, one should keep in mind that progress in philosophy, if there is any, is much slower than in the sciences because the relevant body of evidence is not rapidly expanding. But if this is true, it takes much longer for a philosophical view to become outdated. 
Therefore, it might make sense to treat historical figures as colleagues regarding issues that progress sufficiently slowly for their views to not be outdated. Second, and more importantly, progress in philosophy, if there is such a thing, need not be linear. There is always the danger of regression by virtue of overlooking relevant perspectives or methods. Hence, the study of the classic philosophers might function as a corrective to avoid the pitfalls of regression, even if there is some progress in philosophy.

Let me now turn towards a more powerful argument for skepticism about truth-related progress in philosophy, which is closely related to the standard view of philosophy mentioned in the introduction. As far as I know, Andrew Melnyk (2008) was the first to endorse this argument from persistent disagreement in print. ${ }^{6}$ Here is my reconstruction of his argument:

(1) Philosophers' beliefs do not collectively converge over time.

(2) If there is no collective convergence in philosophy, then there is no collective truth-related progress in philosophy either.

(3) Therefore, there is no collective truth-related progress in philosophy.

The two premises of this argument look extremely plausible - at least initially. Anyone who has had some experience with philosophy will also have gathered anecdotal evidence that philosophers almost always and persistently disagree. This view is expressed in Melnyk's and Hacker's statements quoted above ('Philosophers are no closer to achieving consensus ... than they were in Plato's day' (Melnyk 2008: 208); 'There is no general, agreed body of philosophical knowledge....' (Hacker 2009: 130)). It also seems to be confirmed by the 2009 PhilPapers Survey of philosophers' beliefs that was recently analysed by Bourget \& Chalmers (2014). So premise 1 seems difficult to reject. Premise (2) turns out to be conceptually true if

\footnotetext{
${ }^{6}$ Chalmers (2015: 7) offers a more restricted version of this argument that supports skepticism about philosophical progress on the big questions rather than general skepticism about progress in philosophy.
} 
one keeps in mind that truth-related progress is defined as 'convergence to truth'. It does not entail the reverse and false conditional that collective convergence is sufficient for collective truth-related progress.

I will now argue that, despite its initial plausibility, the argument from persistent disagreement is not sound since (1) is false after all. If we look more closely at what really happens in philosophy, we find a vast number of almost universally and persistently accepted instances of newly accumulated knowledge and corrected errors in philosophy. Here is a list of my favourite examples that can be continued ad libitum:

1 Knowledge is not identical with justified true belief (Gettier 1963). (Almost everyone accepted this immediately after confronting Gettier cases.)

2 There is rigid designation. (Even die-hard descriptivists accepted that in the Kripke cases reference does not correlate with description (Kripke 1980).)

3 Incompatibilist conceptions of free will run the risk of confusing free will with luck. If one's decision is not determined by one's own reasons, then it seems to be a matter of pure luck that the decision is what it is. (Current proponents of incompatibilism still see Hume's challenge as a basic threat to their position (Hume 1975: 96).)

4 Moral facts supervene on descriptive truths about an action. (Richard Hare pointed out that there cannot be a moral difference between two actions unless there is a descriptive difference between them (Hare 1952).)

5 What ought to be the case cannot be deduced from what is the case. (Hume's insight that it is a fallacy to derive normative conclusions from purely descriptive premises has become nearly universally accepted (Hume 1978: 469).) 
6 The 'a priori' and the 'necessary' are neither the same nor necessarily correlated. (Kripke's claims that the former is an epistemic concept whereas the latter is a metaphysical concept and that each can be instantiated apart from the other have been widely accepted (Kripke 1980).)

7 Resemblance nominalism fails because of its limited explanatory power. (Armstrong's argument (Armstrong 1989) has been widely accepted. Nevertheless, he admits that this is not a victory over nominalism in general. There are other kinds of nominalism such as, e.g., trope theory that cannot be ruled out in this way.)

8 Epistemic theories of truth are no longer tenable. (At the end of a lively debate about epistemic theories of truth in the 1980s and 1990s, it turned out that even with the help of strong idealisation, epistemic theories of truth do not work. This has been accepted by the vast majority of experts. Nevertheless, the correct positive view of truth is still controversial.)

9 The principle of the identity of indiscernibles is false. (Max Black's 1952 counterexample of a very simple universe that contains nothing but two indistinguishable spheres has been widely accepted.)

10 Analytic behaviourism is false. (The view that all mental concepts can be analysed in terms of behavioural dispositions was refuted by Hilary Putnam's conceivable case of a Super-Spartan (Putnam 1963: 332-334) who has no disposition to show his strong pain.)

11 Analytic phenomenalism is false. (Roderick Chisholm's argument (Chisholm 1957) that statements about the objective physical world cannot be translated into counterfactual statements about sense experiences was widely accepted and marked the end of analytic phenomenalism.)

12 All classic proofs of God's existence fail. 
13 There is widespread agreement that skepticism about the external world is unreasonable. (According to the 2009 PhilPaper Survey, only $4.8 \%$ of professional philosophers are skeptics.)

As I have indicated above, I believe that this list could be continued, perhaps not endlessly but with many more entries. What does the existence of this (presumably very long) list show? If it is true of every entry on the list that it is currently widely accepted although this was not always the case, then this clearly indicates collective convergence. That would be evidence for the falsity of premise (1), though it is not positive evidence for truth-related progress since, as already noted, collective convergence may also be convergence to the false.

Do we find collective convergence of philosophical views on just about everything? Or is there a particular pattern in the propositions that philosophers tend to agree upon over time? In this regard, the following three observations are relevant. First, collective convergence of philosophical views is limited in extension. Although such convergence does not seem to be a rare exception, there are far more cases of persistent disagreement. Second, there is much more convergence on what counts as an error (standard definition of knowledge, deducing 'ought' from 'is', confusing the a priori with necessity, resemblance nominalism, epistemic theories of truth, the principle of the identity of indiscernibles, analytic behaviourism, analytic phenomenalism) or a bad argument (classic proofs of God's existence, arguments for external world skepticism) than on positive answers. Third, agreed-upon positive views (rigid designation, moral supervenience) are almost always restricted to highly specific issues rather than being answers to big and central questions of philosophy.

Thus, on the one hand, it is simply not true that there is no collective convergence of views in philosophy, as premise (1) of the above argument from persistent disagreement claims. On the other hand, collective convergence in philosophy seems to be severely restricted in several ways: there are fewer cases of such convergence than in the sciences, we 
find convergence much more often concerning errors than concerning positive views, and there is a significant lack of converging positive answers to the big philosophical questions. Although there is no good reason to accept progress skepticism, a moderate position such as the limited progress view seems reasonable. ${ }^{7}$ However, one should not be too pessimistic. Some philosophers claim that the identification of errors is of no help in finding positive answers to our big questions (see Brennan 2010: 10). But this is an overstatement. Often there is only a limited number of plausible answers to a given question. By eliminating the candidates one by one, the number of available options is typically reduced so that at a certain time in the future only one position will be left. ${ }^{8}$ Sometimes we even achieve the positive answer by one single step of elimination. Consider the principle of the identity of indiscernibles. Just by finding out that this principle is false we discover that there can be two things exactly alike in the universe. At other times, the method of elimination has brought us nearer to a positive answer, albeit not yet all the way. When we found out that resemblance nominalism is false, this did not tell us what types really are. Nor does it even rule out all kinds of nominalism. Something similar is true for theories of truth. By simply ruling out epistemic theories, we cannot decide whether a version of the correspondence theory or deflationism or even primitivism is true. But there is no principled reason why the method of elimination should not lead us to a positive view, at least in the long run. We may already have achieved this for the problem of our knowledge about the external world. As the PhilPapers Survey suggests, external world skepticism is widely rejected nowadays. Hence, this big problem might already be solved by the method of elimination.

\section{Why is there so little truth-related progress in philosophy?}

\footnotetext{
${ }^{7}$ This view is also endorsed by Chalmers (2015).

${ }^{8}$ This need not always be the case. Sometimes, the method of elimination leads to a sophisticated revision of the rejected theory.
} 
If what I have said so far is basically correct, there is no reason to doubt that there is at least some truth-related progress in philosophy. But there is still a big difference between the degree of truth-related progress in philosophy and in the hard sciences. Chalmers (2015) nicely illustrates this difference by citing a list of twenty-three unsolved mathematical problems that Hilbert compiled in 1900 , of which ten have now clearly been solved. The case of philosophy looks very different - in particular if we consider the big philosophical problems such as, e.g., the problem of our knowledge of the external world, the problem of the ultimate nature of reality, the mind-body problem, the problem of the fundamental principle(s) of ethics, the problem of free will, the problem of God's existence, and the question whether rationalism or empiricism is correct. Hardly any of these problems have been uncontroversially solved, ${ }^{9}$ although most of them have been discussed much longer than those on Hilbert's list.

So why is there so little truth-related progress in philosophy? The explanation we are looking for must be a differential one. What we want to understand is why there is so much less progress in philosophy than there is in the hard sciences. In his attempt to come up with such an explanation, Chalmers (2015: 16) points towards a very striking difference between the hard sciences and philosophical discourse: 'The hard sciences have methods ... that have the power to compel agreement on the answers to the big questions. Philosophy has a method - the method of argument - that does not.' Whereas the (hard) sciences work with consensus premises 'that are regarded by the community as undeniable' - namely confirmed observation or mathematical axioms - and rely on consensus inferences, in philosophy, premises and inferences always remain disputable: 'There are certainly many arguments for strong conclusions in philosophy. But in the majority of cases, they have premises that opponents

\footnotetext{
${ }^{9}$ Although this observation is basically correct, it is sometimes overstated. For example, Chalmers (2015: 10) claims that the discussion of none of the problems raised by Russell in his The Problems of Philosophy has 'led to universal convergence and almost none have led to anything close.' But skepticism about the external world and idealism with respect to the external world, two of the problematic views discussed by Russell, have clearly become minority positions.
} 
can deny without too much cost, or inferences that opponents can reject without too much cost' (2015: 16). Chalmers seems quite right in pointing to this difference. Consider, e.g., the debate between the skeptic and the Moorean. Whereas the skeptic argues from some general epistemic principles to the conclusion that we do not possess knowledge of the world, the Moorean cannot believe this conclusion and therefore doubts the truth of at least one of the epistemic principles that is used in the skeptic's argument. One person's modus ponens is another person's modus tollens.

The following seems true: if we can rely on practically indisputable premises and inference rules, then the arguments will lead to collective agreement. If, however, premises and inference rules remain disputable, as seems to be the case in philosophy, then the method of argumentation will not lead to collective convergence. But what is the deeper explanation for this difference? Chalmers tries to come up with such an explanation (Chalmers 2015: 259). But, as he frankly admits (see Chalmers 2015: 27-8), most of the explanations he considers suffer from one or the other of the two following problems: they either apply only to parts of philosophy, or they can be applied to the hard sciences as well. The plurality of starting points may be explained by anti-realism, a strong emotional attachment to one's moral views, or verbal disputes. But we cannot apply these explanatory strategies across the board in philosophy. Not every domain in philosophy can be plausibly analysed in an anti-realist manner. Not every philosophical position depends on implicit moral opinions. And there are surely substantial disagreements in philosophy that cannot be reduced to verbal disputes. On the other hand, one might claim that philosophy is extremely abstract, or that we are not evolutionarily well-adapted to philosophising, or that our philosophical views are strongly influenced by the schools and universities we attended and the teachers who trained us. But this also applies to, e.g., theoretical physics. So Chalmers is not really able to provide a good differential explanation of why philosophy, but not physics, has the striking feature of premise and inference deniability. 
In what follows, I will propose a twofold alternative explanation of what Chalmers, on my view, correctly describes as the key difference between philosophy and the hard sciences: its premise and inference deniability. Whereas Chalmers thinks that it is a specific weakness of the philosophical method that it cannot compel agreement, ${ }^{10} \mathrm{I}$ would prefer a different diagnosis: the problem with philosophy as a discipline is that there is no single agreed-upon method of philosophy, as there is in physics or mathematics. Typically, when philosophical opponents cannot resolve their disagreement, this is not just because they have different opinions to start with but also because they rely on different implicit methodologies. For example, in the controversy between the skeptic and the Moorean, the parties seem to rely on different methods: the skeptic takes intuitions about epistemic principles extremely seriously, whereas the Moorean starts with common sense assumptions that should not turn out to be massively mistaken (Moore 1959: 226). As another example, consider the controversy between a utilitarian and someone who objects to utilitarianism by pointing to cases in which maximising utility would lead to actions that we intuitively judge as highly unfair. Typically, the utilitarian will not accept moral intuitions about single cases as counterevidence (Singer 2005). Again, the first-order disagreement depends on a deeper methodological disagreement. If this is correct, then widespread and persistent philosophical disagreement partly stems from deeper methodological disagreements about the correct evidential basis.

If there is no agreement about the proper evidential basis in philosophy, this can also explain why there are no consensus inferences. Of course, philosophers typically do not dispute the rules of deductive logic. But when it comes to abduction or inference to the best explanation, we find pluralism about the correct balancing of theory virtues. Someone like David Lewis will regard the theory-related value of explanatory power more highly than the

\footnotetext{
${ }^{10}$ See Chalmers (2015: 25): 'There is less convergence in philosophy because the philosophical method has less power to compel agreement, and it has less power because of the phenomenon of premise deniability: arguments for strong conclusions in philosophy ... almost always have premises or inferences that can be rejected without too much cost.'
} 
value of being parsimonious, but others, such as David Armstrong, will prefer parsimony. In philosophy, the validity of these different inferential dispositions cannot be calibrated by checking the truth of predictions against an agreed evidential basis because, as we just saw, there is no such agreed evidential basis. So in philosophy, the plurality of inferential habits cannot be reduced but instead proliferates. In contrast, in the sciences, the validity of inferential habits can be calibrated based on their success in prediction. This explains why there is more consensus in science than in philosophy with respect to inferences.

There is a further explanation of why persistent disagreement is much more widespread in philosophy than it is in the hard sciences: in the latter, one typically gets closer to the truth by making contact with reality within restricted domains, while in the former things are far more interconnected - so that one must get it right everywhere in order to make contact with reality at any point. This holistic and multi-disciplinary integration challenge (see Peacocke 1999, Ch. 1) is typical for philosophy. Consider, e.g., the theory of modality. When one attempts to design an adequate semantics for our common modal discourse, one must, at the same time, keep an eye on one's metaphysical commitments to modal reality, and one must also be able to explain how such a kind of reality can be epistemically accessible to us. Hence, semantic, metaphysical, and epistemological questions are interwoven. The same is true for normative ethics that are not fully neutral with regard to meta-ethics or to epistemologies that have some heavyweight metaphysical implications (consider, e.g., virtue epistemology's commitment to stable mental dispositions). So in contrast to the hard sciences, philosophy is a strongly holistic and multi-disciplinary enterprise in which we can only be successful if we keep an eye on nearly everything when we want to solve a specific problem in one discipline. This feature of philosophical work makes it much more probable that philosophers will make small but highly influential errors somewhere on the periphery.

\section{Lessons from my diagnosis of the meagre degree of convergence in philosophy}


If my somewhat speculative and sketchy remarks about the sources of limited collective progress in philosophy are on the right track, two general lessons can be drawn. First, since (often tacit) methodological differences underlie widespread persistent first-order disagreement, philosophy should turn more explicitly towards its own methods. In fact, this fits the new meta-philosophical turn in philosophy that brings topics such as the sources of philosophical knowledge (e.g. naturalism, pragmatism, conceptual analysis or rational intuitions, and experimental philosophy), the cognitive goals of philosophy, disagreement in philosophy, philosophical progress, and the role that the history of philosophy has for philosophy into the focus of philosophical reflection. Without directly addressing and solving methodological disputes in philosophy, we cannot expect to make more progress. Second, the above-mentioned integration challenge suggests that it is more important for philosophy than for the hard sciences that philosophers not only specialise but also have a broader and more integrative view of philosophy that pays tribute to philosophy's intra-disciplinary interrelations.

However, my diagnosis of the limited progress in philosophy also has implications regarding the role that the history of philosophy has for (systematic) philosophy. As I have noted above, philosophy makes slower progress than, e.g., physics since its body of evidence is not rapidly expanding over time. For this reason, philosophical classics do not become outdated so quickly and hence can be discussed as if they were the work of contemporary colleagues for a longer time. But there is more to say about the role of the history of philosophy. Since the disagreement about the correct method for philosophy is still not settled, the method that is dominant at a certain time is largely determined by sociological trends rather than by arguments. But then there is a real threat that there are no fully rational methodological strictures at any particular time. Reflections on the history of philosophy, including the multiplicity of methods that have been accepted at different times, may serve as a corrective against a too restrictive methodological view at any given time. Moreover, 
because it is a highly complex discipline, philosophy encourages philosophers to specialise and divide cognitive labour. ${ }^{11}$ This tendency is at least in part counterproductive, given the holistic and integrative requirements for proper solutions. Here again, the history of philosophy might serve as a corrective, since the great philosophers of the past typically entertained views that offered big, integrative pictures. I do not want to claim that only by reflecting on its own history can philosophy avoid becoming methodologically onedimensional and overspecialised. There are certainly other means to achieve this goal. However, reflection on the history of philosophy, with its huge reservoir of diverse philosophical methods and big picture views, is especially well-suited to counterbalance philosophical strictures. $^{12}$

Even if the history of philosophy is instrumentally valuable for doing systematic philosophy, it can be approached in very different ways. Melnyk (2008: 216-17) distinguishes between pure and impure history of philosophy. Anyone who practices pure history of philosophy is interested in the accurate historical contextualisation of the relevant text, reads the text in its original language, and is not selective in her attention. In contrast, impure practitioners do not interpret the relevant text in its historical context, can read the text in translation, are selective in their attention, and do not give too much weight to exegetical accuracy; sometimes it will even do to study classic texts only through the eyes of an expert. However, when it is used as a corrective to methodological and topical confines, it seems to suffice that one does history of philosophy in an impure manner.

\section{Conclusion}

\footnotetext{
${ }^{11} \mathrm{Cf}$. Bieri (2007) for a critical view on this feature of current philosophy.

12 Glock (2008) distinguishes different claims about the instrumental value of the history of philosophy for systematic philosophy. Historiophobia takes the history of philosophy to be dysfunctional for proper philosophical thinking. Pragmatic historicism claims that the history of philosophy may be helpful, though it is not essential to philosophising. In contrast, mainline historicism claims exactly this: that the history of philosophy is essential to philosophy. Using Glock's distinction, I am defending pragmatic historicism here.
} 
In this paper I have argued that, among the many conceptions of cognitive progress, truthrelated progress plays the most pertinent role for scientific disciplines. It turns out that the prospects of general arguments for scepticism about truth-related progress in philosophy are dim. A more attractive route to such kind of progress scepticism in philosophy relies on the observation that there is widespread persistent disagreement among philosophers. Since a discipline's truth-related progress requires collective convergence over time, persistent disagreement indicates a substantial lack of such progress. However, a long list of paradigm cases helps to support the claim that there is less persistent disagreement in philosophy than professional philosophers typically believe. Nevertheless, progress on the big and central issues in philosophy seems clearly to be limited, at least much more limited than in the hard sciences. This calls for a differential explanation. As I have argued, Chalmers' own suggestion, namely that premises and inferences in philosophy remain always disputable, does not cut deep enough. At the end of the day it is the unmitigated methodological pluralism in philosophy that offers a comprehensive explanation. Given the generally slow progress in philosophy and its so far unmitigated methodological pluralism, reflection on philosophy's own history may provide us with a helpful corrective. In this respect, the history of philosophy may have instrumental value for doing systematic philosophy. ${ }^{13}$

\footnotetext{
${ }^{13}$ Acknowledgements: Earlier drafts and parts of this paper were presented on a number of different occasions: at a workshop on Was bedeutet der aktuellen Philosophie ihre Geschichte? Zur Methodologie der Philosophie? at the Humboldt University Berlin in February 2013, at a workshop on What does philosophy owe to its history? at the Institute for Advanced Studies in Humanities (KWI) Essen in April 2015, and at a lecture series on disagreement in philosophy at the University of Zurich in April 2015. Substantial comments from Dominik Balg, Merrie Bergmann, Anne Burkard, Joachim Horvath, Jens Kipper, Steffen Koch, Jan Wieben, and Marcel van Ackeren helped me to work out a significantly revised final version of this paper.
} 


\section{References}

Armstrong, D. (1989), Universals: An Opinionated Introduction (Boulder, Westview Press).

Beckermann, A. (2008), 'Analytische Philosophie: Peter Bieris Frage nach der richtigen Art, Philosophie zu betreiben', Deutsche Zeitschrift für Philosophie, 56: 599-613.

Bieri, P. (2007), 'Was bleibt von der Analytischen Philosophie?', Deutsche Zeitschrift für Philosophie, 55: 333-44.

Black, M. (1952), 'The Identity of Indiscernibles', Mind, 62: 153-64.

Bourget, D. \& Chalmers, D. (2014), 'What Do Philosophers Believe?', Philosophical Studies, 170: 465-500.

Brennan, J. (2010), ‘Scepticism About Philosophy', Ratio, 61: 1-16.

Chalmers, D. (2015), 'Why Isn’t There More Progress in Philosophy?', Philosophy, 90: 3-31.

Chisholm, R. (1957), Perceiving: A Philosophical Study (Ithaca \& London, Cornell University Press).

Chisholm (1976), Person and Object: A Metaphysical Study (New York \& London: Routledge).

Dietrich, E. (2010), 'There is No Progress in Philosophy', Essays in Philosophy, 12: 329-44.

Ernst, G. (2013), ‘Fortschritt in der Philosophie?', Information Philosophie, 41: 8-15.

Gettier, E. (1963), 'Is Justified True Belief Knowledge?', Analysis, 23: 121-23.

Glock, H. (2008), 'Analytic Philosophy and History: A Mismatch?', Mind, 117: 867-97.

Hacker, P.M.S. (2009), 'A Contribution, Not to Human Knowledge, But to Human Understanding', in: A. O’Hear (ed.), Conceptions of Philosophy (New York, Cambridge University Press), 129-53.

Hare, R.M. (1952), The Language of Morals (Oxford, Clarendon Press). 
Hume, D. (1975), Enquiry Concerning Human Understanding and Concerning the Principles of Morals, 3rd ed. (Oxford, Oxford University Press).

Hume, D. (1978), A Treatise of Human Nature, 2nd ed. (Oxford, Oxford University Press).

Kenny, A. (2005), 'The Philosopher's History and the History of Philosophy', in: T. Sorell \& G.A.J. Rogers (eds), Analytic Philosophy and the History of Philosophy (Oxford, Oxford University Press), 13-24.

Kim, J. (1989), 'Mechanism, Purpose, and Explanatory Exclusion', Philosophical Perspectives, 3: 77-108.

Kornblith, H. (2010), 'Believe in the Face of Controversy', in: R. Feldman \& T. Warfield (eds), Disagreement (Oxford, Oxford University Press), 29-52.

Kripke, S.A. (1980), Naming and Necessity (Cambridge MA, Harvard University Press).

Lewis, D. (1973), 'Causation', Journal of Philosophy, 70: 556-67.

Melnyk, A. (2008), 'Philosophy and the Study of Its History', Metaphilosophy, 39, 203-19.

Moore, G.E. (1959), 'Four Forms of Scepticism', in: G.E. Moore, Philosophical Papers (London \& New York, Routledge), 196-226.

Nudler, O. (2001), 'Is there Progress in Philosophy?', Principia, 5: 241-52.

O'Connor, T. (2000), Persons and Causes: The Metaphysics of Free Will (Oxford, Oxford University Press).

Pappas, G. (2014), 'Internalist vs. Externalist Conceptions of Epistemic Justification', in E.N. Zalta (ed.), The Stanford Encyclopedia of Philosophy, URL = <http://plato.stanford.edu/archives/fall2014/entries/justep-intext/>.

Peacocke, C. (1999), Being Known (Oxford, Oxford University Press).

Putnam, H. (1963), 'Brains and Behavior', in: H. Putnam (1975), Mind, Language, and Reality: Philosophical Papers, Vol. 2 (Cambridge, Cambridge University Press), 32541. 
Rapaport, W.J. (1982), 'Unsolvable Problems and Philosophical Progress', American Philosophical Quarterly, 19: 289-98.

Singer, P. (2005), 'Ethics and Intuitions', Journal of Ethics, 9: 331-52.

Sorell, T. (2005), 'On Saying No to History of Philosophy', in: T. Sorell \& G.A.J. Rogers (eds), Analytic Philosophy and the History of Philosophy (Oxford, Oxford University Press), $\quad 43-59$. 